\title{
Chapter 10 \\ The Alpha and Omega of Teacher \\ Education: Organizing Mathematical \\ Activities
}

In future not instruction and receptivity, but organisation and activity will be the special mark of the teaching/learning process.

Johannes Kühnel (1869-1928)

\section{Introduction}

The aim of this paper is to describe an introductory mathematics course for primary student teachers and to explain the philosophy behind it.

The paper is structured as follows: It starts with a general plea for placing the mathematical training of any category of students into their professional context. Then the context of primary education in Germany, with its strong emphasis on the principle of learning by discovery, is sketched. The third and main section of the paper presents the "O-script/A-script method", a special teaching/learning format for stimulating student teachers' mathematical activities along the principle of learning by discovery. In Sect. 4 special attention is given to the notion of proof in the context of primary teacher education. The paper concludes with some observations of how student teachers evaluate this approach.

\section{Mathematics in Contexts}

It is a most remarkable phenomenon that the teaching and learning of mathematics at the university level which was hardly a subject of public discussion in the past is now attracting world wide attention. The Discussion Document for the ICMI Study on this topic (ICMI 1997) lists five external reasons for this changing attitude:

1. the increase in the number of students who are attending tertiary institutions;

2. pedagogical and curriculum changes that have taken place at the pre-university level; 
3. the increasing differences between secondary and tertiary mathematics;

4. the rapid development of technology;

5. demands on universities to be accountable.

I would like to add an internal reason and to comment on it: the changing views about the nature of mathematics. The first three-quarters of this century witnessed a steady rise of formalism and structuralism culminating in Bourbaki's monolithic architecture of mathematics. However, by the end of the seventies this programme despite its success in some fields of mathematics turned out as a failure as a universal programme, as did similar structuralistic programmes in other areas, for example linguistics and architecture. At that time it was widely recognized that in no field of study could semantics be replaced by syntax. Postmodern philosophy rediscovered the meaningful context as an indispensable aspect of all human activity, including mathematical activity. As far as details of the changing views of mathematics are concerned I refer to Davis and Hersh (1981) and Ernest (1998).

As a consequence, we have to conceive of "mathematics" not solely as an academic field of study but as a broad societal phenomenon. Its diversity of uses and modes of expression is only in part reflected by the kind of specialized mathematics which we typically find in university departments. I suggest a use of capital letters to describe MATHEMATICS as mathematical work in the broad sense including mathematics in science, engineering, economics, industry, commerce, craft, art, education, daily life, and so forth, and including the customs and requirements specific to these contexts. Of course, specialized mathematics is a central part of MATHEMATICS. But mathematicians cannot and must not claim a monopoly for the whole. It is unjustified to assume that any piece of mathematics would form an absolute body of knowledge carrying its potential applications in itself. In his paper "The pernicious influence of mathematics on science" J.T. Schwartz used drastic words to warn mathematical specialists of applying mathematics to other fields without paying proper attention to the context (Schwartz 1986).

The consequences for the teaching and learning of mathematics at the university should be clear: In teaching mathematics to non-specialists the professional context of the addressees has to be taken fundamentally and systematically into account. The context of mathematical specialists is appropriate for the training of specialists, not for the training of non-specialists.

In the present paper the professional context to be considered is teaching mathematics at the primary level. There are mathematicians who look down on this task. In my view this is a fundamental mistake. The importance of primary mathematics within MATHEMATICS can hardly be overestimated. After all, it is at this level where the systematic encounter of children with mathematics begins and where the points for their whole mathematical education are set. I would like to refer here to the wisdom of the Tao-te-ching:

Plan difficult things at the very beginning when they are still easy.

Care for big things as long as they are still small. 
Although many elements of the context of primary teacher education are specific the general approach adopted in this paper might be interesting for developing mathematical courses for other professional fields, too.

\section{The Context of Teacher Education}

Since the beginning of the 1980s the development of primary education in the State of North Rhine-Westphalia has exerted a great influence on the other German States. ${ }^{1}$ The boundary conditions for primary mathematics education in North Rhine-Westphalia are special in two respects:

1. In the first phase ${ }^{2}$ of their education at the university all primary student teachers have to study three subjects: German language, mathematics and a third subject (for example, environmental education, physical education, art, etc.). One of the three subjects has to be chosen as a major subject (45 credit hours out of the 120 credit hours of the whole 3-year programme). Two other (minor) subjects cover 25 credit hours. $^{3}$ As a consequence mathematics is compulsory for all primary student teachers. Roughly $90 \%$ of them choose mathematics as a minor subject ( 25 credit hours).

2. The syllabus for primary schools (grades 1 to 4) adopted in 1985 marked an important turning point in the history of public education in Germany. For the first time the principle of learning by discovery was explicitly prescribed as the basic principle of teaching and learning (Kultusminister des Landes NordrheinWestfalen 1985, Sect. 3):

The tasks and objectives of mathematics teaching are best served by a conception in which learning mathematics is considered as a constructive and investigative process. Therefore teaching has to be organized such that children are offered as many opportunities as possible for self-reliant learning in all phases of the learning process:

1. starting from challenging situations; stimulating children to observe, to ask questions, to guess;

2. exposing a problem or a complex of problems for investigation; encouraging individual approaches; offering help for individual solutions;

3. relating new results to known facts in a diversity of ways; presenting results in a more and more concise way; assisting to memory storage; stimulating individual practice of skills;

4. talking about the value of new knowledge and about the process of acquiring it; suggesting the transfer to new, analogous situations.

\footnotetext{
${ }^{1}$ With 17 million people Northrhine-Westfalia is the largest German State.

${ }^{2}$ The first phase ( 3 years) is followed by the second phase ( 2 years) which is spent at special institutions in close proximity of schools.

${ }^{3} 25$ credit hours are for general education (pedagogy, psychology, ...).
} 
The task of the teacher is to find and to offer challenging situations, to provide children with substantial materials and productive ways of practising skills, and, above all, to build up and sustain a form of communication which serves the learning processes of all children.

This emphasis on mathematical processes instead of ready-made subject matter is visible in other parts of the syllabus, too. For example, the first section "Tasks and objectives" lists the following four "general objectives" of mathematics teaching: Mathematizing, Exploring, Reasoning and Communicating. Obviously, these objectives reflect basic components of doing mathematics at all levels. The fourth section of the syllabus describes in some detail why mathematical structures on the one hand and applications of mathematics on the other hand are two sides of one coin and how these two aspects can be interlocked in teaching. The explicit statement of this complementarity is also novel for German primary schools.

The development of this new syllabus was certainly very much influenced by similar developments in other European countries, in particular, the Netherlands. However, there has also been a strong trend towards active learning within German mathematics education. At the beginning of this century, Johannes Kühnel, one of the leading figures of progressive education in Germany, wrote his famous book "Neubau des Rechenunterrichts" ("Reconstructing the Teaching of Arithmetic") in which he described the "teaching/learning method of the future" as follows (Kühnel 1954, 70):

The learner will no longer be expected to receive knowledge, but to acquire it. In future not instruction and receptivity, but organisation and activity will be the special mark of the teaching/learning process.

Since the late eighties considerable progress has been made in developing practical approaches and materials for this new conception of primary mathematics teaching including innovative textbooks (cf. Winter 1987; Wittmann and Müller 1994-1997, and Becker and Selter 1996). The project Mathe 2000 has played a leading role in this development. Of course the implementation of these materials depends crucially on the teachers' ability to abandon the deeply rooted instruction/receptivity model of teaching and learning in favour of the organisation/activity model. However, as experience shows, it is not enough just to describe new ways of teaching in general terms. The natural way to stimulate and to support the necessary change within the school system is to restructure teacher education according to the organisation/activity model. Only teachers with first hand experiences in mathematical activity can be expected to apply active methods in their own teaching as something natural and not as something imposed from outside. Therefore all efforts in preservice and in-service teacher education have to be concentrated on reviving student teachers' and teachers' mathematical activity.

Interestingly, the new emphasis on student activity is not restricted to teacher education, it is a general phenomenon of the present discussion about teaching mathematics at the university level (cf. the section "Student Activity" in ICMI 1997). More and more mathematicians are taking special care of stimulating student activities. Bill Jacob's "Linear Functions and Matrix Theory" (Jacob 1995) is a good example. 


\section{The O-Script/A-Script Method}

The traditional pattern of introductory mathematics courses at German universities is a combination of a 2 to 4 hours per week lecture ("Vorlesung") on the one hand and 2 hours of practice ("Übungen") which take place in groups of about 30 students on the other hand. I am well aware that expository teaching can be very stimulating and that work in groups based on good problems can arouse students' thinking and communication as well. Nevertheless I contend that grosso modo the lecture/practice pattern has a strong inherent tendency towards instuction and receptivity: Often the tasks and exercises offered to students for elaboration require mainly or even merely a reproduction of the conceptual and technical tools introduced in the lecture. So more or less students' individual work and work in groups tends to be subordinated to the lecture. Frequently, work in groups degenerates into a continuation of the lecture: The graduate student responsible for the group just presents the correct solutions of the tasks and exercises.

The lecture/practice format is particularly common in courses for large groups of students. In fact if you are confronted with numbers of students as large as 400 to 600 , as we are in our primary teacher education programme, there is a strong pressure towards instuction/receptivity, and it is hard to think of alternatives.

However, the more I got involved in developmental research along the lines of learning by discovery the more I felt the contradiction between the teaching/learning model which I followed in my mathematical courses and the teaching/learning model which I recommended in my courses in mathematics education.

The O-script/A-script method has been developed as an attempt to mitigate this cognitive conflict. The basic idea, the Alpha and Omega, of this method is very simple: Just take Johannes Kühnel literally in teacher education and replace "instruction and receptivity" by "Organisation and Activity", that is, use both the lecture and the group work for organizing student activities.

An essential ingredient of this new teaching/learning format is a clear distinction between the text written down by the lecturer on the blackboard or the overhead projector and the text elaborated by the individual student. As the lecturer's main task is to organize students' learning her or his text is called the "O-script". It is not a closed text, but it contains many fragments, leaves gaps, and often gives only hints. Therefore it is a torso to be worked on. As the elaborated text expresses the student's individual activity it is called the "personal A-script".

The regulations of our teacher education programme do not allow for making the A-script obligatory. However, the A-script can be used as an additional qualification by students who fail the final test. Experience shows that the majority of student teachers is willing to write an A-script. How to organize students' activity in a lecture? In trying to find an answer to this question I got inspired by two quotations:

We should teach more along problems than along theories. A theory should be developed only to the extent that is necessary to frame a certain class of problems. (Giovanni Prodi) The main goal of all science is first to observe, then to explain phenomena. In mathematics the explanation is the proof. (David Gale) 
Accordingly, I divided the course in two parts: The first part was devoted to introducing and clarifying a list of 50 carefully selected generic problems which should be elaborated in the A-scripts. The second systematic part should present a theoretical framework for these problems, however, based on students' experiences in writing the A-scripts. The second part did not differ from ordinary lectures. I think this format absolutely appropriate at this place of the learning process. Actually, I don't see a substitute for it.

The following areas which are closely related to the contents of the primary curriculum were covered in the course: (1) Place Value Systems, (2) Elementary Combinatorics, (3) Arithmetic Progressions, (4) Sequences, (5) Elementary Number Theory.

These areas are rich playgrounds for genuine mathematical activities. By using the opportunities offered in the course student teachers acquire not only the appropriate background knowledge which enables them to look at the primary curriculum from a higher level. They also acquire first-hand experiences in mathematizing, exploring, reasoning, and communicating.

The 10 problems selected for the area "Arithmetic Progressions" are as follows:

1. (From Butts 1973.) Try to decompose the set $\{1,2,3, \ldots, n\}$ of the first $n$ natural numbers into two subsets such that the sum of the numbers in one subset is equal to the sum of the numbers in the other subset. For which $n$ is this possible? For which $n$ not?

2. Investigate the analogous problem for the set $\{2,4, \ldots, 2 n\}$ of the first $n$ even numbers.

3. Investigate the analogous problem for the set $\{1,3, \ldots, 2 n-1\}$ of the first $n$ odd numbers.

4. Which numbers can be represented as sums of consecutive numbers?

5. Which numbers can be represented as sums of 2 (or $3,4, \ldots$ ) consecutive numbers?

6. In how many ways can 1000 be represented as a sum of consecutive numbers?

7. In how many ways can 1000 be represented as a sum of consecutive odd numbers?

8. From Monday to Friday 60 little lambs were born on a pasture: on Tuesday 3 more than on Monday, on Wednesday 3 more than on Tuesday, on Thursday 3 more than on Wednesday, and on Friday 3 more than on Thursday. How many lambs were born on each day?

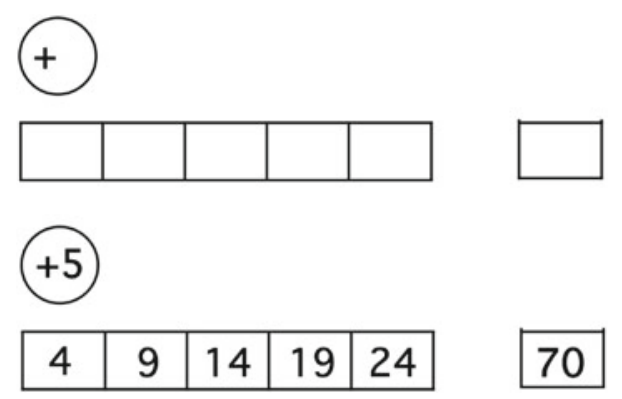

Fig. 1 Steinbring's problem 
9. (From Steinbring 1997). In the scheme of Fig. 1 the number in the circle (the "addition number") and the number in the first box ("the starting number") can be chosen arbitrarily. The numbers in the other four boxes are calculated inductively according to the following rule (see the example in Fig. 1): The number in a box is the number in the preceding box plus the addition number. The numbers in all five boxes are added to give the final result (the "target"). How to choose the starting number and the addition number in order to get the target 50? How many solutions do exist? Which numbers can be obtained as targets?

(In this problem and the next one natural numbers and the number 0 are admitted.)

10. Investigate the same problem for 6 boxes instead of 5 .

The list of these 10 problems has been constructed by employing the "method of generating problems" (Wittmann 1971). So the use of heuristic strategies is ensured. Problem 8 is taken from a textbook for grade 4, problem 9 from a paper on the findings of a teaching experiment based on this problem. Therefore student teachers can see explicit connections with the primary curriculum. ${ }^{4}$ As these connections are reinforced in the subsequent maths education course the maths courses become meaningful for student teachers within their professional context.

In the first part of the course each weekly lecture introduced 5 problems to the student teachers for investigation. The problems were explained in full detail and it was indicated how these problems could be attacked in different ways by using various "enactive", "iconic" and "symbolic" representations. The main heuristic strategies as described, for example, in Polya (1981), Mason (1982) or Schoenfeld (1985), were explained by referring to the problems of the course. However, no solutions were given.

The student teachers had less problems with developing ideas. The real challenge was how to formulate a coherent text. "What should an A-script look like?" was a frequent question. So parts of the lecture as well as of the group work had to address this difficulty. Referring to some examples I indicated in my lectures how the gaps of the O-script can be filled to get an A-script. In addition, student teachers were allowed to submit drafts of their A-scripts for critical reading, and could revise them according to the comments they received.

At the end of the first part of the course the students (at least the brave ones) had intensively worked on 50 selected problems. Even when they hadn't solved all problems properly, they had experienced a variety of mathematical phenomena. This was a good basis for the theoretical framework developed in the subsequent second part of the course.

For example, the problems on arithmetic progressions were theoretically framed by proofs of the sum formula and of the following remarkable theorem by J.J. Sylvester: The number of representations of a number $n$ as a sum of consecutive numbers is equal to the number of odd divisors of $n$.

Both proofs were based on ideas that had been developed by students before.

\footnotetext{
${ }^{4}$ After their own work on problem 9 student teachers were shown a video on a teaching experiment in which a group of 12 fourth graders had found all solutions within 30 minutes.
} 
Interestingly, the extended work on problems in the first part paid off in the second part: the course "covered" the same mathematical content as courses in the ordinary format usually do.

\section{Operative Proofs}

As stated at the beginning, the basic tenet of the present paper is that the mathematical training of student teachers should reflect their professional context. This requirement is particularly critical when it comes to proofs.

It should be obvious that the notion of formal proof related to deductively structured theories is inappropriate or even counterproductive as a background for appreciating "Reasoning" as an objective of primary mathematics. That is not to say, however, that the notion of proof is irrelevant for primary mathematics. On the contrary. Fortunately, contemporary views of proof allow for an intellectually honest incorporation of proof into both primary teacher education and primary teaching. Studies in the history and philosophy of mathematics have destroyed the long held formalistic doctrine that the only rigorous form of proof is a formal proof. It has turned out that the notion of formal proof has its clear limitations, particularly from the point of view of the practising mathematician (cf., for example, Branford 1913, Hardy 1929, Thom 1973, Davis and Hersh 1981, Atiyah 1984, Long 1986 and Thurston 1994). In a letter submitted to the working group on proof at ICME 7, Québec 1992, Yuri I. Manin expressed his broader understanding of "proof as a journey" very nicely:

Many working mathematicians feel that their occupation is discovery rather than invention. My mental eye sees something like a landscape; let me call it a "mathscape". I can place myself at various vantage points and change the scale of my vision; when I start looking into a new domain, I first try a bird's eye view, then strive to see more details with better clarity. I try to adjust my perception to guess at a grand design in the chaos of small details and afterwards plunge again into lovely tiny chaotic bits and pieces.

Any written text is a description of a part of the mathscape, blurred by the combined imperfections of vision and expression. Every period has its own social conventions, and the aesthetics of the mathematical text belong to this domain. The building blocks of a modern paper (ever since Euclid) are basically axioms, definitions, theorems and proofs, plus whatever informal explanations the author can think of.

Axioms, definitions and theorems are spots in a mathscape, local attractions and crossroads. Proofs are the roads themselves, the paths and the highways. Every itinerary has its own sightseeing qualities, which may be more important than the fact that it leads from $A$ to $B$.

With this metaphor, the perception of the basic goal of a proof, which is purportedly that of establishing "truth" is shifted. A proof becomes just one of many ways to increase the awareness of a mathscape.

Any chain of argument is a one-dimensional path in a mathscape of infinite dimensions. Sometimes it leads to the discovery of its end-point, but as often as not we have already perceived this end-point, with all the surrounding terrain, and just did not know how to get there.

We are lucky if our route leads us through a fertile land, and if we can lure other travellers to follow us. 
In mathematics education this new view of proof has been reflected in many papers (cf., for example, de Villiers 1997). Based on Semadeni's and Kirsch's proposals of "pre-mathematical" or "pre-formal" proofs (Semadeni 1974; Kirsch 1979), the concept of "operative proof" has been developed (Wittmann 1997). An operative proof is a proof which is embedded in the exploration of a mathematical problem context and which is based on the effects of operations exerted thereby on meaningfully represented mathematical objects.

For this reason operative proofs explain phenomena which were observed before (cf. Gale's statement quoted above) and thus they contribute to understanding mathematics.

As also non-symbolic representations can be used operative proofs are particularly useful for the early grades and for primary teacher education. I would like to demonstrate this by giving two examples from my introductory course on arithmetic.

Example 1 (Infinity of primes) The formal proof of the infinity of prime numbers runs as follows: Let us assume that the set of prime numbers is finite: $p_{1}, p_{2}, \ldots, p_{r}$. The number $n=p_{1} p_{2} \ldots p_{r}+1$ has a divisor $p$ that is a prime number. Therefore $n$ is divisible by one of the numbers $p_{1}, \ldots, p_{r}$. From $p \mid n$ and $p \mid p_{1} p_{2} \ldots p_{r}$ we conclude that $p$ also divides the difference $n-p_{1} p_{2} \ldots p_{r}=1$. However, $p \mid 1$ is a contradiction of the fact that 1 is not divisible by a prime number. Therefore the assumption was wrong.

The following operative proof of the infinity of primes is based on the representation of natural numbers on the number line. One of the problems that the student teachers had to investigate was the determination of primes by means of the sieve of Eratosthenes. Therefore they knew from their own experience how the sieve works. Using this knowledge the infinity of primes can be proved just by explaining why the iterative sieve procedure does not stop: Assume that in finding primes we have arrived at a prime number $p$. Then $p$ is encircled and all multiples of $p$ are cancelled. The product

$$
n=2 \times 3 \times 7 \times 11 \times \ldots \times p
$$

is a common multiple of all primes sieved out so far. So it was cancelled at every previous step of the procedure. As no cancellation process following the selection of a prime can hit adjacent numbers the successor of $n$ has not been cancelled yet. Therefore after every step there are numbers left and the smallest of them is a new prime number.

Example 2 (Sylvester's theorem) In the first part of the course the student teachers worked with arithmetic progressions and investigated the representation of natural numbers as sums of consecutive numbers. Based on their experiences the following operative proof of Sylvester's theorem emerged in a natural way: Sums of consecutive numbers are represented as staircases. Depending on the parity of the number of stairs, each staircase can be transformed into a rectangular shape that represents a product. If the parity is odd, there is a middle stair and the upper part of the staircase can be cut off and added to the lower part (Fig. 2). 

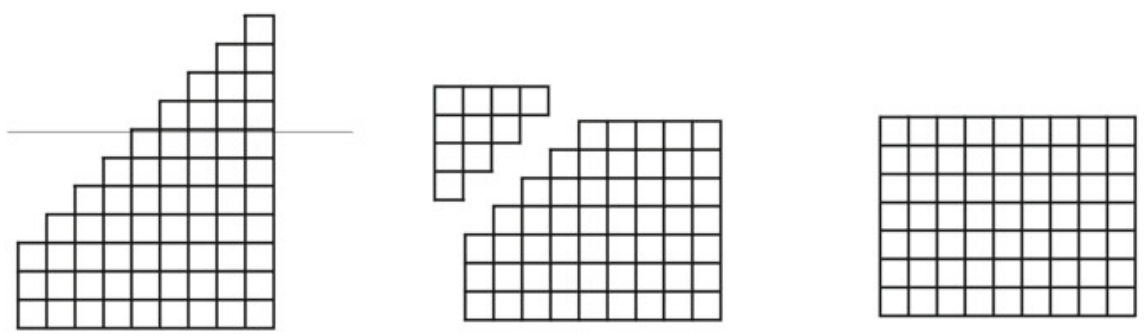

Fig. 2 Operative proof of Sylvester's theorem, case 1
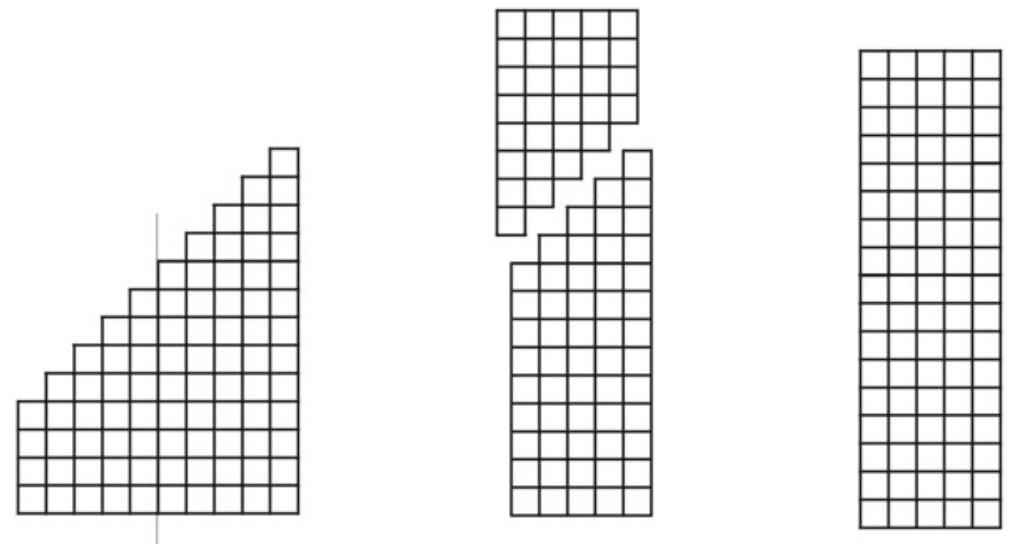

Fig. 3 Operative proof of Sylvester's theorem, case 2

If the parity of stairs is even then the staircase can be divided vertically in the middle and the two parts fit together to make a rectangular shape (Fig. 3).

A careful study of the effects of these two operations shows that in both cases an odd divisor of the represented number arises: either the number of stairs or the sum of the heights of the first and last stair (which must be odd for an even number of stairs). As a consequence any staircase representation of a number gives rise to an odd factor of $n$. But the converse is also true: A rectangle with an odd side can be transformed into a staircase of one of the two types depending on the relative size of the odd factor. A closer inspection reveals that this relationship between staircase representations and rectangular representations of $n$ is bijective.

Again this operative proof explains phenomena which are well known from previous work on problems.

The advantage of operative proofs in the context of teacher education is obvious: These proofs are not separated from this context but closely related to it. In becoming acquainted with operative proofs student teachers learn to appreciate the use of informal means of representation for doing mathematics at early levels. Often, elements of such activities in teacher education can immediately be implanted into 
primary teaching. Consider, for example, the following exercise from a textbook for the second grade:

$$
\begin{aligned}
& 1+2+3= \\
& 2+3+4= \\
& 3+4+5= \\
& 4+5+6=
\end{aligned}
$$

Looking at the results children discover the times 3-row. If the sums are represented by three columns of counters, the displacement of one counter to make a rectangle is obvious. This work with counters is a good and in my view also a necessary preparation for algebra where the same exercise can be resumed as follows:

$$
(a-1)+a+(a+1)=3 a .
$$

\section{Experiences with the Course}

Feedback from student teachers collected by means of a questionnaire after the introductory course on elementary geometry showed that the "O-script/A-script" method was accepted by $75 \%$ of the population. The writing of the A-script was experienced as a very time-consuming, but effective exercise. In the same vein $70 \%$ affirmed that their understanding of the principle of learning by discovery had been improved.

However, only $59 \%$ of the students indicated that the course had had a more or less positive influence on their view of mathematics. $41 \%$ expressed their concerns about the openness of the first part. This result is not surprising as at school many students are programmed as receivers of knowledge. The adopted definitely mechanistic and formalistic attitude towards mathematics gives them a feeling of security and helps them "to survive". Feeling comfortable with mechanistic routines in the system of school and university (!) they do not want to be confronted with uncertainty.

The unfavourable influence of mathematical experiences from school is particularly apparent in student teachers' preconceptions of operative proofs. An instructive example was reported in Wittmann and Müller (1990). In a seminar student teachers studied figurate numbers. ${ }^{5}$ In particular trapezoid numbers were introduced as a composition of square and triangular numbers (see Fig. 4).

In looking for patterns the students guessed that for all $n$ the trapezoid number ' $T_{n}$ and $n$ leave the same remainder modulo 3. For this relationship an operative proof (at that time called "iconic proof") was given which was based on the corresponding pattern.

\footnotetext{
${ }^{5}$ In history figurate numbers played a fundamental role as a cradle of number theory. We are convinced that these numbers are also a wonderful context for stimulating mathematical activities in children. As a consequence figurate numbers play an important role in "mathe 2000".
} 


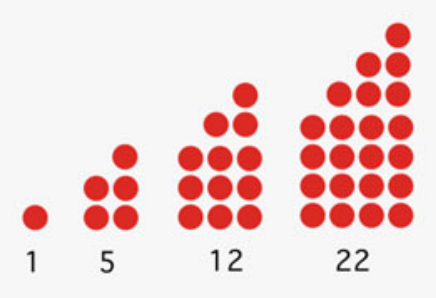

$$
T_{n}=n^{2}+(n-1) n / 2=\left(3 n^{2}-n\right) / 2 .
$$

Fig. 4 Trapezoid numbers

Right after this demonstration some students expressed their doubt on its validity. The teacher didn't intervene and quickly the whole group agreed that the demonstration could only claim the status of an illustration, not the status of a proof. The teacher then offered a formal proof and confronted it with the operative proof. The student teachers were invited to think about these two types of proof and to write down their opinions. The papers showed very clearly how the student teachers' appreciation of operative proofs was inhibited by the understanding of proof that they had acquired at school. For illustration I quote from some papers:

The symbolic proof is to be preferred because it is more mathematical.

The iconic proof is much more intuitive for me and explains much better what the problem is. For me the inferences drawn from patterns of dots are convincing and sufficient as a proof. Unfortunately we have not been made familiar with this type of proof at school. Only symbolic proofs have been taught.

The iconic proof is very intuitive. One understands the connections from which the statement flows. I can't imagine how a counterexample could be found, because it does not matter how many 3-columns can be constructed. In my opinion it is nevertheless not a proof, but only a demonstration, which, however, holds for all $n$. At school I learned that only a symbolic proof is a proof.

The symbolic proof is more mathematical. This proof is more demanding, as some formulae are involved which you have to know and to recall. The iconic proof can be followed step by step, and each step is immediately clear. However, I wonder if an iconic proof would be accepted in examinations.

Cognitive conflicts in accepting operative proofs as valid proofs have to be understood as natural symptoms of a metamorphosis lifting student teachers to higher professional levels. Experience shows that in retrospect student teachers consciously appreciate teacher education programmes which are embedded in the professional context. In a recent survey by the centre of teacher education at the University of Dortmund 2700 student teachers in North Rhine-Westphalia in their second phase of training were asked to evaluate the courses in mathematics and mathematics education they had received in the first phase of their training at the university (Zentrum für Lehrerbildung 1997). The results are very encouraging (Fig. 5). The evaluations of the programmes at the universities Paderborn and Dortmund which share the same philosophy were much higher than those of the six other universities in North Rhine-Westphalia which offer courses in primary teacher education. 


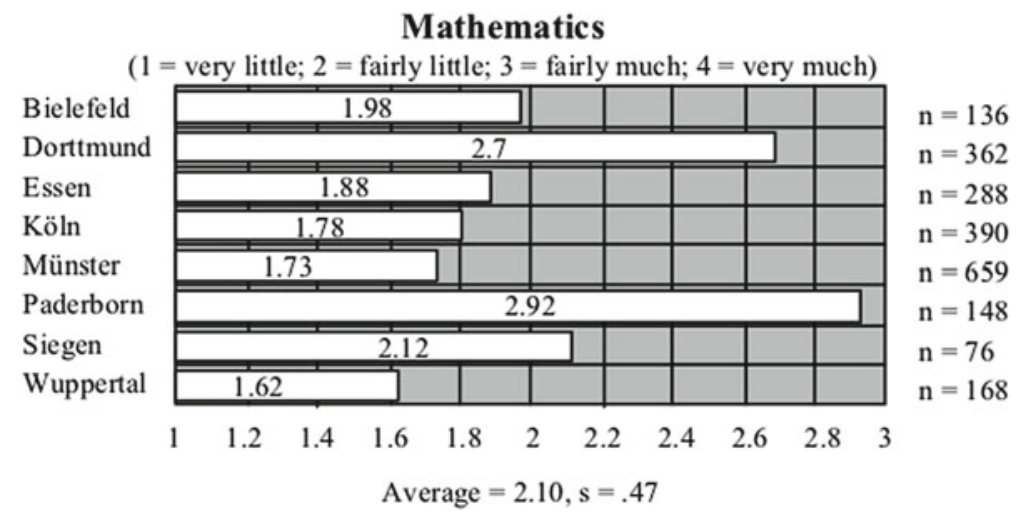

Fig. 5 Results of the empirical study

A team of 16 authors has just written a book "Arithmetic as a Process" (Müller et al. 2004) which is based on the O/A approach to teacher education described in this paper. This book is a truly mathematical book, but unlike other books it consciously puts mathematics in the context of teacher education-neither by sacrificing education to mathematics nor mathematics to education.

\section{References}

Atiyah, M.: Interview with Michael Atiyah. Math. Intell. 6, 9-19 (1984)

Becker, J., Selter, C.: Elementary school practices. In: Bishop, A., Keitel, C., Laborde, C., Clements, K., Kilpatrick, J. (eds.) International Handbook of Mathematics Education, Part 1, pp. 511-564. Dordrecht, Kluwer (1996)

Branford, B.: Betrachtungen über mathematische Erziehung vom Kindergarten bis zur Universität. Teubner, Leipzig (1913)

Butts, T.: Problem Solving in Mathematics. Elementary Number Theory and Arithmetic. Glenview, III, Scotts Foresman (1973)

Davis, P., Hersh, R.: The Mathematical Experience. Birkhäuser, Boston (1981)

Ernest, P.: A postmodern perspective on research in mathematics education. In: Sierpinska, A., Kilpatrick, J. (eds.) Mathematics Education as a Research Domain: A Search for Identity, An ICMI Study, Book 1, pp. 71-85. Dordrecht, Kluwer (1998)

Hanna, G.: Rigorous Proof in Mathematics Education. Ontario Institute for Studies in Education, Toronto (1983)

Hardy, G.H.: Mathematical Proof. Mind 38(149), 1-25 (1929)

ICMI: On the Teaching and Learning of Mathematics at the University Level. Discussion Document. ICMI Bulletin, No. 43, 3-13 (1997)

Jacob, B.: Linear Functions and Matrix Theory. Springer, New York (1995)

Kirsch, A.: Beispiele für prämathematische Beweise. In: Dörfler, W., Fischer, R. (eds.) Beweisen im Mathematikunterricht, pp. 261-274. Wien, Hölder-Pichler-Tempsky/Teubner (1979)

Kühnel, J.: Neubau des Rechenunterrichts. Bad Heilbrunn, Klinkhardt (1954)

Kultusminister des Landes Nordrhein-Westfalen: Richtlinien und Lehrpläne für die Grundschule in Nordrhein-Westfalen. Mathematik, Köln (1985) 
Long, R.: Remarks on the history and philosophy of mathematics. American Mathematical Monthly 93, 609-619 (1986)

Mason, J.: Thinking Mathematically. Addison Wesley, London (1982)

Müller, G.N., Steinbring, H., Wittmann, E.C. (eds.): 10 Jahre "mathe 2000", Bilanz und Perspektiven. Leipzig, Klett (1997)

Müller, G.N., Steinbring, H., Wittmann, E.C.: Arithmetik als Prozess. Klett, Leipzig (2004)

Polya, G.: Mathematical Discovery. On Understanding, Learning and Teaching Problem Solving. Combined Edition. Wiley, New York (1981)

Schoenfeld, A.: Mathematical Problem Solving. Academic, New York (1985)

Schwartz, J.T.: The pernicious influence of mathematics on science. In: Kac, M., Rota, G.C., Schwartz, J.T. (eds.), Discrete Thoughts. Essays on Mathematics, Science and Philosophy, pp. 19-25. Boston, Birkhäuser (1986)

Semadeni, Z.: The Concept of Premathematics as a Theoretical Background For Primary Mathematics Teaching. Polish Academy of Mathematical Sciences, Warsaw (1974)

Steinbring, H.: Epistemological investigation of classroom interaction in elementary mathematics teaching. Educ. Stud. Math. 32, 49-72 (1997)

Thom, R.: Modern mathematics - Does it exist? In: Howson, G. (ed.) Developments in Mathematical Education, pp. 194-212. Cambridge, CUP (1973)

Thurston, W.P.: On proof and progress in mathematics. Bull. Am. Math. Soc. 30(2), 161-177 (1998)

de Villiers, M. (ed.): Proceedings of Topic Group 8 "Proofs and Proving: Why, when, and how?", ICME 8 Seville, Spain, 1996. Centrahill, Ass. Math. Ed. South Africa (1997)

Winter, H.: Mathematik entdecken. Neue Ansätze für den Mathematikunterricht in der Grundschule. Frankfurt a.M., Scriptor (1987)

Wittmann, E.C.: Complementary attitudes in problem solving. Educ. Stud. Math. 4, 241-253 (1971)

Wittmann, E.C.: Operative proofs. In: de Villiers, M. (ed.), Proceedings of Topic Group 8 "Proofs and Proving: Why, When, and How?", ICME 8 Seville, Spain, 1996, pp. 15-22. Centrahill, Ass. Math. Ed. South Africa (1997)

Wittmann, E.C., Müller, G.N.: When is a proof a proof? Bull. Soc. Math. Belg. I, Ser. A 42, 15-42 (1990)

Wittmann, E.C., Müller, G.N.: Das Zahlenbuch. Mathematik für die Grundschule (4 vols.). Leipzig, Klett (1994-1997)

Zentrum für Lehrerbildung.: Grundschullehrer(innen)-Ausbildung zwischen Fachwissenschaft, Fachdidaktik und Praxis. Universität Dortmund, ZfL-Info 2, 7-12 (1997)

Open Access This chapter is licensed under the terms of the Creative Commons Attribution 4.0 International License (http://creativecommons.org/licenses/by/4.0/), which permits use, sharing, adaptation, distribution and reproduction in any medium or format, as long as you give appropriate credit to the original author(s) and the source, provide a link to the Creative Commons license and indicate if changes were made.

The images or other third party material in this chapter are included in the chapter's Creative Commons license, unless indicated otherwise in a credit line to the material. If material is not included in the chapter's Creative Commons license and your intended use is not permitted by statutory regulation or exceeds the permitted use, you will need to obtain permission directly from the copyright holder. 